\title{
Basic surgical skills training influences career choices of medical undergraduates
}

\begin{abstract}
Aim: The aim of this study was to evaluate if the implementation of basic surgical skills training to medical undergraduates affects the attitudes of students to surgery and to assess if it makes surgery a more attractive career option.
\end{abstract}

Methods: An unbiased convenience sample of third year medical students was recruited for the basic surgical skills training. Modified questionnaires already in use were utilised to evaluate the perception of students to the course and to assess if it made surgery a more attractive career option for them.

Results: 12 third year medical students began and finished the skills training course successfully. Over $90 \%$ of students believed it essential that newly qualified doctors should be able to suture, scrub up adequately and adhere to sterile procedure. $91.7 \%$ of students believed it should be a component of the medical undergraduate curriculum and $100 \%$ believed this course made surgery a more attractive career option for them

Conclusion: This study shows that medical students view the incorporation of basic surgical skills training into the medical undergraduate curriculum favourably. Surgical skills training make surgery a more attractive career option for students.
Volume I Issue I - 2014

\author{
Peter M Neary,' Mark Regan,' Myles R \\ Joyce,' Oliver J McAnena,' Liam Duffy, ${ }^{2}$ \\ Pauline Joyce ${ }^{3}$ \\ 'Department of Surgery, University College Hospital Galway, \\ Ireland \\ ${ }^{2}$ Beaumont Hospital/Institute of Leadership, Royal College of \\ Surgeons in Ireland, Ireland \\ ${ }^{3}$ Institute of Leadership, Royal College of Surgeons in Ireland, \\ Ireland
}

Correspondence: Peter M Neary, Department of Surgery, University College Hospital Galway, Ireland, Tel 00353-86-

3619234,Email peterneary@hotmail.com

Received: August 31, 2014 | Published: September

30,2014

Keywords: surgery, education, career choice, students, medical

\section{Introduction}

Graduates of a medical undergraduate degree have numerous career options available to them. Hence, deciding their final career pathway amongst this vast array of options available can be a large source of anxiety to newly qualified doctors. The majority of doctors apply for training in a chosen career pathway in their first six months following graduation. This offers them little or often no opportunity to get hands on work experience following graduation in their chosen career pathway prior to applying for these training schemes. In fact, most doctors decide which branch of medicine to pursue based on their exposure during their undergraduate training.

Surgery as a core subject in the medical undergraduate curriculum encompasses the acquisition of anatomical, biochemical, physiological, immunological and pathological knowledge relevant to surgical disease. However, surgery is predominantly a craft based speciality which medical students have minimal access to. If students are not exposed to the art of surgery as a craft, this may hinder doctors considering surgery as a genuine career option considering the words of Atkins et al. "You wouldn't buy a car without taking a test drive so why choose a career without trying it out first?". The hypothesis of this study considers whether exposure of medical undergraduates to practical basic surgical skills training may help doctors make a more informed decision when choosing their career pathway.

\section{Materials and methods}

Based on alphabetical order, groups of third year medical students had been divided into groups of 12students for clinical placement by the university at the start of the academic year. One of these groups was randomly chosen as the convenience sample to participate. The first six months of clinical placement during the curriculum appears to be the most influential period of training that can affect what career medical students pursue. ${ }^{3}$ The skill training was provided within three months of commencement of clinical attachments. 12third year medical students were asked to participate of which all were agreeable. Skillsets taught included basic suturing, bowel anastomosis and laparoscopy. The teaching was hands on with experienced surgeons initially showing how to perform the chosen skill and then supervising the students performing the same tasks in groups of two. All 12 participating students successfully attended and completed the training.

Immediately prior to commencement and immediately following course completion, students completed modified established questionnaires indicating career preference and their own perceived suitability to pursuing a career in surgery. Questionnaire completion was anonymous. Data from both time points was then compared. Following course completion, questionnaires targeting students' attitudes to this additional component of medical undergraduate teaching were also obtained. While there was no formal evaluation of the skills or knowledge gained by students, student perception of what they learned and assessment if this had changed their attitudes to surgery as a surgical career choice was also documented through a modified established questionnaire. ${ }^{4,5}$

\section{Results}

The 12 third year medical students consisted of eight from Ireland, two from Malaysia, one from Australia and one from Japan. The 
average age was 22years (range 20-25). Male to female ratio was five out of 12 . Table 1 describes the preferred speciality of students rated from one to three prior to and following basic surgical skills training. Prior to and following skills training, surgery was the most popular choice for students. Interestingly, following completion of basic surgical skills training, surgery was the only speciality that increased in its first choice popularity from $41.7 \%$ to $50 \%$.

Table 2 outlines the students' perceptions of whether they had a skillset compatible with surgery and if they were considering a career in surgery prior to and following completion of the skills training course respectively. Interestingly, $75 \%$ of students agreed that they had a skillset compatible with surgery following completion of the course compared to $58.3 \%$ prior to course commencement. Table
3 outlines what skills the students analysed believe to be essential, desirable or not applicable to newly qualified doctors. Remarkably, over $90 \%$ of students believed it essential that newly qualified doctors should be able to suture, be able to scrub up adequately and be adhere to sterile procedure.

Table 4 describes the student perception of basic surgical skills training having completed the basic surgical skills course. $91.7 \%$ believe it should be a component of the medical undergraduate curriculum. 83.3\% students felt it should be assessed as part of the undergraduate curriculum. Remarkably, $100 \%$ of students believed this basic surgical skills training course made surgery a more attractive career option for them and similarly all students desired further surgical skills training as part of their curriculum.

Table I Speciality preference rated from one to three prior to and following skills course

\begin{tabular}{|c|c|c|c|c|c|c|}
\hline \multirow[b]{2}{*}{ Preference } & \multicolumn{3}{|c|}{ Prior to skills course } & \multicolumn{3}{|c|}{ Following skills course } \\
\hline & First(\%) & Second $(\%)$ & Third(\%) & First(\%) & Second $(\%)$ & Third(\%) \\
\hline Surgery and subspecialties(n) & $5(41.7)$ & $2(16.7)$ & $0(0)$ & $6(50)$ & $1(8.3)$ & $1(8.3)$ \\
\hline General Practitioner(n) & $2(16.7)$ & $1(8.3)$ & $3(25)$ & $2(16.7)$ & $1(8.3)$ & $2(16.7)$ \\
\hline Paediatrics(n) & $0(0)$ & $1(8.3)$ & $3(25)$ & $0(0)$ & $2(16.7)$ & $2(16.7)$ \\
\hline Internal Medicine and subspecialties(n) & $3(25)$ & $4(33.3)$ & $2(16.7)$ & $2(16.7)$ & $3(25)$ & $3(25)$ \\
\hline Emergency medicine(n) & $2(16.7)$ & $3(25)$ & $1(8.3)$ & $2(16.7)$ & $3(25)$ & $2(16.7)$ \\
\hline Obstetrics-gynaecology(n) & $0(0)$ & $0(0)$ & $3(25)$ & $0(0)$ & $1(8.3)$ & $2(16.7)$ \\
\hline Other(n) & $0(0)$ & $1(8.3)$ & $0(0)$ & $0(0)$ & $1(8.3)$ & $0(0)$ \\
\hline
\end{tabular}

Table 2 Student perception prior to and following skills course

Prior to skills course
Following skills course
Agree/strongly agree(\%)
Disagree/strongly disagree $(\%)$
Neutral(\%)
Agree/strongly agree(\%)
Disagree/strongly disagree $(\%)$
Neutral(\%)

\begin{tabular}{|c|c|c|c|c|c|c|}
\hline $\begin{array}{l}\text { Skillset } \\
\text { compatible } \\
\text { with } \\
\text { surgery(n) }\end{array}$ & $7(58.3)$ & $3(25)$ & $2(16.7)$ & $9(75)$ & $1(8.3)$ & $2(16.7)$ \\
\hline $\begin{array}{l}\text { Considering } \\
\text { pursuing } \\
\text { a career in } \\
\text { surgery(n) }\end{array}$ & $8(66.7)$ & $4(33.3)$ & $0(0)$ & $8(66.7)$ & $3(25)$ & $1(8.3)$ \\
\hline
\end{tabular}


Table 3 Student perception of what skills newly qualified doctors should have

\begin{tabular}{|c|c|c|c|}
\hline & Essential(\%) & Desirable(\%) & Not applicable(\%) \\
\hline Be able to describe operative procedures(n) & $7(58.3)$ & $5(41.7)$ & $0(0)$ \\
\hline Adequate knowledge of relevant regional anatomy(n) & 11(91.7) & $1(8.3)$ & $0(0)$ \\
\hline Be able to describe the surgical approach(n) & $7(58.3)$ & $5(41.7)$ & $0(0)$ \\
\hline Appreciate standard theatre etiquette and protocols(n) & $10(83.3)$ & $2(16.7)$ & $0(0)$ \\
\hline Be able to scrub-up adequately(n) & 11(91.7) & $0(0)$ & $1(8.3)$ \\
\hline Be able to adhere to sterile procedures(n) & $12(100)$ & $0(0)$ & $0(0)$ \\
\hline Be aware of the risks involved in theatre to self and others(n) & 11(91.7) & $1(8.3)$ & $0(0)$ \\
\hline Be aware of the risks involved in theatre to patients(n) & 11(91.7) & $1(8.3)$ & $0(0)$ \\
\hline Be aware of the role of the various theatre personnel(n) & $8(66.7)$ & $4(33.3)$ & $0(0)$ \\
\hline Be familiar with basic instruments(n) & $5(41.7)$ & $7(58.3)$ & $0(0)$ \\
\hline Be able to suture(n) & 11(91.7) & $1(8.3)$ & $0(0)$ \\
\hline Know how to perform basic surgical operations(n) & $4(33.3)$ & $7(58.3)$ & $1(8.3)$ \\
\hline Be able to perform basic surgical operations(n) & $4(33.3)$ & $5(41.7)$ & $3(25)$ \\
\hline Be able to assist(as second assistant)(n) & $7(58.3)$ & $4(33.3)$ & $1(8.3)$ \\
\hline Be aware of the potential complications of surgery(n) & 11(91.7) & $1(8.3)$ & $0(0)$ \\
\hline Appreciate the need for careful peri-operative monitoring(n) & 11(91.7) & $1(8.3)$ & $0(0)$ \\
\hline
\end{tabular}

Table 4 Student perception of basic surgical skills training

\begin{tabular}{lccc}
\hline & Yes(\%) & No(\%) & Don't know(\%) \\
\hline $\begin{array}{l}\text { Should basic surgical skills training be a component of the medical undergraduate } \\
\text { curriculum?(n) }\end{array}$ & $11(91.7)$ & $0(0)$ & $1(8.3)$ \\
$\begin{array}{l}\text { Should basic surgical skills be assessed as a component of the medical undergraduate } \\
\text { curriculum?(n) }\end{array}$ & $10(83.3)$ & $0(0)$ & $2(16.7)$ \\
$\begin{array}{l}\text { Would undergraduate surgical skills training attract more doctors to pursue a career in } \\
\text { surgery?(n) }\end{array}$ & $10(83.3)$ & $0(0)$ & $2(16.7)$ \\
$\begin{array}{l}\text { Has this surgical skills training workshop made surgery a more attractive surgical career } \\
\text { option for you?(n) }\end{array}$ & $12(100)$ & $0(0)$ & $0(0)$ \\
$\begin{array}{l}\text { Would you like to have more surgical skills training workshops like this as part of your } \\
\text { curriculum?(n) }\end{array}$ & $12(100)$ & $0(0)$ & $0(0)$ \\
\hline
\end{tabular}

\section{Discussion}

Graduates of a medical undergraduate degree have an array career options available to them. Hence, deciding their final career pathway can be a large source of anxiety for newly qualified doctors. Doctors are exposed to these various specialities principally during their undergraduate training. However, levels of exposure to the various specialities available to doctors as a career is extremely variable as well as the content of the exposure. The majority of doctors make their career choice early in their undergraduate training. ${ }^{1}$ This lack of exposure may hinder students in their career decision making ability.

Surgery as a core subject in the medical undergraduate curriculum encompasses the acquisition of anatomical, biochemical, physiological, immunological and pathological knowledge relevant to surgical disease. Surgery is predominantly a craft based speciality. However, students have minimal access to the craft based element of this speciality. If students are adequately exposed to the art of surgery as a craft, this may help doctors make a more informed decision when choosing their career pathway.

Clinical skills training is often described as one of the weakest aspects of the medical undergraduate curriculum. ${ }^{6}$ Surgical skills training is neglected in most undergraduate curriculums leaving students poorly exposed to the craft based aspects of surgery. Considering skills labs and simulators have become commonplace in post-graduate training and have become very advanced in mimicking reality, this atmosphere provides the ideal safe training environment to 
teach students basic surgical skills. A study conducted by Birch et al. found that students perceived basic surgical principles highly relevant and the majority felt that the level of proficiency they achieved at undergraduate level to be much less than anticipated.

This study showed that over $90 \%$ of students felt basic surgical skills are essential for newly qualified doctors and basic surgical skills training should be part of the medical undergraduate curriculum. Furthermore, following completion of the basic surgical skills training course, more students wanted to pursue a career in surgery, more students felt that they had the appropriate skills to pursue a career in surgery and all students felt it made surgery a more attractive career option to them.

The study population in this study was kept small which is a limitation to this study. This negated the possibility to include any meaningful statistical analysis in this study. The most significant findings with this study show that over $91 \%$ of students viewed basic surgical skills essential and should be a component of the medical undergraduate curriculum and $100 \%$ believed this course made surgery a more attractive career option for them. Although, it was clear that any increase to this study population would not add a meaningful alteration to any of these conclusions, the conclusion and findings would certainly be strengthened significantly if numbers were higher. Furthermore, the lack of an adequate control group is also a limitation to this study.

In conclusion, the results of this study show that the incorporation of basic surgical skills training for medical undergraduates makes surgery a more attractive career option for them. Furthermore, students believe basic surgical skills are essential for newly qualified doctors and basic surgical skills training should be part of their curriculum. The findings of this study support the expansion of basic surgical skills training to be incorporated into the medical undergraduate curriculum.

\section{Acknowledgements}

We wish to acknowledge Ethicon, Johnson \& Johnson (Medical) Ireland for supplying the surgical equipment necessary to cater for the surgical skills training.

\section{Conflict of interest}

The author declares no conflict of interest.

\section{References}

1. Barshes NR, Vavra AK, Miller A, et al. General surgery as a career: a contemporary review of factors central to medical student specialty choice. J Am Coll Surg. 2004;199(5):792-799.

2. Atkins CS. Choosing your career path. Student BMJ. 2011;0.1136/sbmj. d3559.

3. Bland KI, Isaacs G. Contemporary trends in student selection of medical specialties: the potential impact on general surgery. Arch Surg. 2002;137(3):259-267.

4. Fernando N, McAdam T, Cleland J, et al. How can we prepare medical students for theatre-based learning? Med Educ. 2007;41(10):968-974.

5. Scott I, Gowans M, Wright B, et al. Stability of medical student career interest: a prospective study. Acad Med. 2012;87(9):1260-1267.

6. Simunovic VJ, Hozo I, Rakic M, et al. New paradigm in training of undergraduate clinical skills: the NEPTUNE-CS project at the split university school of medicine. Croat Med J. 2010;51(5):373-380.

7. Birch DW, Mavis B. A needs assessment study of undergraduate surgical education. Can J Surg. 2006;49(5):335-340. 